\title{
A Eutectic Mixture of Galactitol and Mannitol as a Phase Change Material for Latent Heat Storage
}

Abhijit Paul, Li Shi , Christopher W. Bielawski

Department of Chemistry and Biochemistry, University of Texas at Austin, 105 E. 24th St. Stop A5300, Austin, Texas 78712, United States

Department of Mechanical Engineering, University of Texas at Austin, 204 E. Dean Keaton St. Stop C2200, Austin, Texas 78712, United States

Department of Chemistry, Ulsan National Institute of Science and Technology (UNIST), 50 UNIST-gil, Ulsan, 689-798, Republic of Korea

\section{ABSTRACT}

The thermophysical properties of mixtures of galactitol and mannitol were examined via differential scanning calorimetry (DSC) and X-ray powder diffraction (XRD) analysis. The aforementioned sugars were found to form a eutectic mixture at 30:70 molar ratio between galactitol and manntitol that displayed a melting point of $153{ }^{\circ} \mathrm{C}$ while maintaining a high latent heat of fusion $\left(\Delta \mathrm{H}_{\text {fus }}=292 \mathrm{Jg}^{-1}\right)$. The XRD data revealed that the eutectic mixture contained the $\alpha, \beta$, and $\delta$ forms of mannitol with the $\delta$ form being the major component. By varying the temperature ramp rates utilized in the DSC measurements from $0.5{ }^{\circ} \mathrm{C} \mathrm{min}-1$ to $20{ }^{\circ} \mathrm{C} \mathrm{min}^{-1}$, the heat of crystallization as well as the crystallization temperature increased (c.f., $\Delta \mathrm{H}_{\text {crys }}: 64 \mathrm{Jg}^{-1} \rightarrow 197 \mathrm{Jg}^{-1} ; \mathrm{T}_{\mathrm{c}}: 68^{\circ} \mathrm{C} \rightarrow 105$ $\left.{ }^{\circ} \mathrm{C}\right)$. In addition, the temperature and the enthalpy of crystallization were also improved by up to $34 \%$ through the addition of small quantities (up to $0.5 \mathrm{wt} \%$ ) of nucleating agents, such as graphite powder and silver iodide. After 100 heating/cooling cycles under nitrogen atmosphere, the heat of fusion of the eutectic mixture was decreased by only $4 \%$ with no change in the melting point, and the mixture appeared to be chemically stable 
according to Fourier transform infrared spectroscopy (FT-IR) spectroscopy. Collectively, these data indicate that the eutectic mixture exhibits excellent cyclic stability under ambient atmospheres and offers potential for use in thermal storage applications.

Keywords: Thermal energy storage (TES), sugar alcohol, galactitol, mannitol, eutectic mixture, phase change material (PCM)

Corresponding author: bielawskilab@gmail.com

\section{Introduction}

High-density thermal energy storage (TES) has been identified as a promising approach for realizing a sustained use of energy for heating and cooling, solar energy harvesting, and other energy-related applications. ${ }^{1}$ To be practical, TES systems require storage materials that display (1) high energy densities, (2) a practical phase change temperature, and (3) high durability. Phase change materials (PCMs), which absorb and release thermal energy when they melt and solidify at nearly constant temperature during the phase transition, offer the potential for meeting the aforementioned requirements. Indeed, paraffin, fatty acids, sugar alcohols and salt hydrates have been used or investigated as PCMs for thermal storage applications. ${ }^{2-8}$ The sugar alcohols such as threitol, allitol, iditol, erythritol, mannitol, dulcitol and their eutectic mixtures are particularly promising candidates for use in TES applications due to their broad range of melting temperatures, high volumetric energy densities, non-corrosive nature, and high thermal stabilities. ${ }^{9}$ As one of the widely studied sugar alcohol based PCMs, erythritol melts between $117-120{ }^{\circ} \mathrm{C}$ and displays a heat of fusion of $340-344 \mathrm{Jg}^{-1} \cdot{ }^{7,10-12}$ The stereoisomers, galactitol and mannitol, have also been investigated as PCMs (see Table 1 for a summary of their thermal data). 
Table 1. A Summary of Thermal Data for Various Sugars.

\begin{tabular}{|c|c|c|c|c|}
\hline Type & $\begin{array}{l}\text { Melting Point } \\
\left({ }^{\circ} \mathrm{C}\right)\end{array}$ & $\begin{array}{l}\text { Heat of Fusion } \\
\qquad\left(\mathrm{J} \mathrm{g}^{-1}\right)\end{array}$ & $\begin{array}{c}\text { Polymorphic } \\
\text { phase }\end{array}$ & Reference \\
\hline \multirow{4}{*}{$\begin{array}{c}\text { Galactitol } \\
\text { (or Dulcitol) }\end{array}$} & 179.8 & 246.4 & - & [13] \\
\hline & 180.3 & 267.9 & - & \\
\hline & 187.2 & 357.4 & & [14] \\
\hline & $186-187$ & 330.0 & - & [15] \\
\hline \multirow[t]{14}{*}{ Mannitol } & 162.2 & 326.8 & - & [8] \\
\hline & 166.0 & 308.2 & $\square$ & [14] \\
\hline & 166.0 & 290.0 & - & [15] \\
\hline & 167.0 & 246.0 & $\beta$ & [16] \\
\hline & 157.0 & 243.0 & $\delta$ & \\
\hline & 166.0 & 294.0 & $\beta$ & [17] \\
\hline & 166.0 & 286.3 & $\alpha$ & \\
\hline & 155.0 & 295.1 & $\delta$ & \\
\hline & 165.0 & 338.0 & $\beta$ & [18] \\
\hline & 165.6 & 302.2 & $\alpha$ & [19] \\
\hline & 165.4 & 297.3 & $\beta$ & \\
\hline & 164.6 & 280.2 & $\gamma$ & \\
\hline & 165.4 & 279.1 & $\delta$ & \\
\hline & 164.1 & 264.3 & $\kappa$ & \\
\hline
\end{tabular}

Recently, Solé et al. explored the potential of using myo-inositol, galactitol, and mannitol as PCMs by differential scanning calorimetry (DSC) and Fourier transform infrared (FTIR) spectroscopy. ${ }^{13}$ As part of that study, myo-inositol was found to undergo polymorphic changes between $50{ }^{\circ} \mathrm{C}$ and $260{ }^{\circ} \mathrm{C}$ and displayed a relatively cyclic thermal stability when analyzed between $150{ }^{\circ} \mathrm{C}$ to $260{ }^{\circ} \mathrm{C}$. For comparison, galactitol showed relatively poor thermal cyclic stability as the crystallization temperature decreased to 60 ${ }^{\circ} \mathrm{C}$ from its initial value of $120{ }^{\circ} \mathrm{C}$ after the eighteenth cycle, and eventually no crystallization was observed after the nineteenth cycle. Similarly, the enthalpies of heating and crystallization displayed by D-mannitol decreased by $30 \%$ and $50 \%$ after 20 
and 50 thermal cycles, respectively. FT-IR spectroscopy analysis of galactitol and Dmannitol after the aforementioned thermal cycles, which were performed under air, indicated that the sugars underwent undesired oxidation to derivatives that displayed relatively low heat capacities.

In general, sugar alcohols with high heats of fusion often exhibit high melting temperatures, which greatly limits the choice of heat transfer fluids to be used in conjunction with sugar alcohol based thermal storage medium. Hence, there is a need to develop sugar-based PCMs that display a relatively low melting temperature without reducing the heat of fusion.

Herein, we report the thermophysical properties of galactitol, mannitol, and their mixtures, and explore their potential for use as PCMs in medium temperature range TES systems. We also study the cyclic, thermal, and chemical stabilities of a eutectic mixture of galactitol and mannitol using differential scanning calorimetry (DSC) and FTIR spectroscopy. The use of various additives to suppress the subcooling of the eutectic mixture was also explored.

\section{Materials and method}

\subsection{Preparation of sugar alcohol mixtures}

Galactitol (or Dulcitol) (99+\%, Alfa aesar) and $\beta$ - $D$-mannitol (99\%, Acros) were used as received. In general, galactitol and mannitol were combined such that the resulting mixture containing $10,20,30,40,50,60,70,80,90$, or $100 \mathrm{~mol} \%$ of mannitol. In a typical procedure, a round-bottomed flask containing galactitol and mannitol mixture was immersed in a pre-heated silicone oil bath maintained at $200{ }^{\circ} \mathrm{C}$. The mixture was then stirred for 15 min to melt both sugars. The resulted liquid mixture was slowly cooled 
to room temperature. In cases where a sparingly soluble salt (see below) was used, the salt was uniformly added to the eutectic mixture of galactitol and mannitol, followed by heating above its melting point, and when mixed with the salt while being stirred.

\subsection{Differential Scanning Calorimetry (DSC)}

DSC studies were performed using a Mettler Toledo DSC823e. Heating and cooling rates of 0.5 to $20{ }^{\circ} \mathrm{C} \min ^{-1}$ were typically employed. All experiments were performed under nitrogen with a flow rate of $50 \mathrm{~mL} \mathrm{~min}^{-1}$. All weight measurements were accurate up to $0.001 \mathrm{mg}$ in a sealed aluminum cell with or without small piercings, where necessary. The DSC was calibrated for heat flow and temperature using an indium and zinc standards. All samples were preheated to $80{ }^{\circ} \mathrm{C}$, allowed to cool down to its crystallization point, and then reheated for data collection. The melting point and heat of fusion were obtained from the second heating cycle and the average value of three independent DSC experiments was used.

\subsection{Thermogravimetric Analysis (TGA)}

The thermal stabilities of sugar alcohols and the aforementioned eutectic mixture was analyzed using a TA instruments (Q50) thermogravimetric analyzer at a scan rate of $10{ }^{\circ} \mathrm{C} \mathrm{min}^{-1}$ under an atmosphere of nitrogen. A typical sample size of 8-10 mg was used for the TGA analyses.

\subsection{FTIR Spectroscopy}

Attenuated total reflection infrared (ATR-IR) spectra were recorded using a ThermoScientific Nicolet iS10 ATR/FT-IR spectroscopy attached to an attenuated total reflection (ATR) apparatus. A resolution of $4 \mathrm{~cm}^{-1}$ and the average of 120 automated scans from 400 to $4000 \mathrm{~cm}^{-1}$ were used to obtain the IR spectra. 


\subsection{Powder X-ray Diffraction Analysis}

Sugar alcohol and mixtures were studied used powder X-ray diffraction in conjunction with DSC to characterize the physical state of the sugar alcohol. X-ray powder diffraction (XRPD) profiles of the samples were obtained using a Philips PW 1050/70 PW 1710 diffractometer fitted with a scintillation counter and $\mathrm{Cu} \mathrm{K} \alpha$ radiation source $($ wavelength $=0.15418 \mathrm{~nm}$ ). The divergence and detector silts were of 0.3 and $0.18^{\circ}$ aperture, respectively. Data were collected between 5 and $50^{\circ}$ of $2-\theta$ in a step mode using a step size of $0.02^{\circ}$ of $2-\theta$ and collecting time of $1 \mathrm{~s}$ per step.

\subsection{Thermal Conductivity Measurements}

The through-thickness thermal diffusivity of cast molded samples of thickness 2 $\mathrm{mm}$ and diameter $10 \mathrm{~mm}$ was measured a laser flash system (Netzsch LFA-457 micro flash). We have calculated $\kappa_{\mathrm{PCM}}$ using the eutectic mixture's specific heat $\left(C_{\mathrm{PCM}}\right)$, measured using a DSC (Netzsch DSC-404 F1 Pegasus), and the measured mass density $\left(\rho_{\mathrm{PCM}}\right)$ to obtain the thermal conductivity as $\kappa_{\mathrm{PCM}}=\alpha_{\mathrm{PCM}} \rho_{\mathrm{PCM}} C_{\mathrm{PCM}}$.

\section{Results and Discussion}

\subsection{Thermophysical properties of galactitol, mannitol, and their mixtures}

The DSC thermograms of pure mannitol and galactitol as well as their mixtures are shown in Figure 1. The amount of galactitol in the mixture decreases as we move from top to bottom in Figure 1. The DSC data of pure galactitol and mannitol revealed sharp endothermic signals that corresponded to the melting process of sugar alcohols. The heat of fusion and the melting point were determined from the melting curve data. For galactitol, the onset of melting peak $\left(\mathrm{T}_{\text {onset }}=\mathrm{T}_{\text {melting }}\right)$ was observed at $186.5{ }^{\circ} \mathrm{C}$ and 
the curve peaked at $187.6{ }^{\circ} \mathrm{C}$. For mannitol, the onset of melting peak was observed at 165.5 ${ }^{\circ} \mathrm{C}$ and the curve peaked at $167.1{ }^{\circ} \mathrm{C}$. The area under the melting curve corresponded to the heat of fusion of that compound and was measured to be $354 \mathrm{~J} \mathrm{~g}^{-1}$ and $301.0 \mathrm{~J} \mathrm{~g}^{-1}$ for galactitol and $\beta$ - $D$-mannitol, respectively. The aforementioned melting points and heats of fusion for the pure sugars were consistent with values reported in the literature. $^{14,19}$

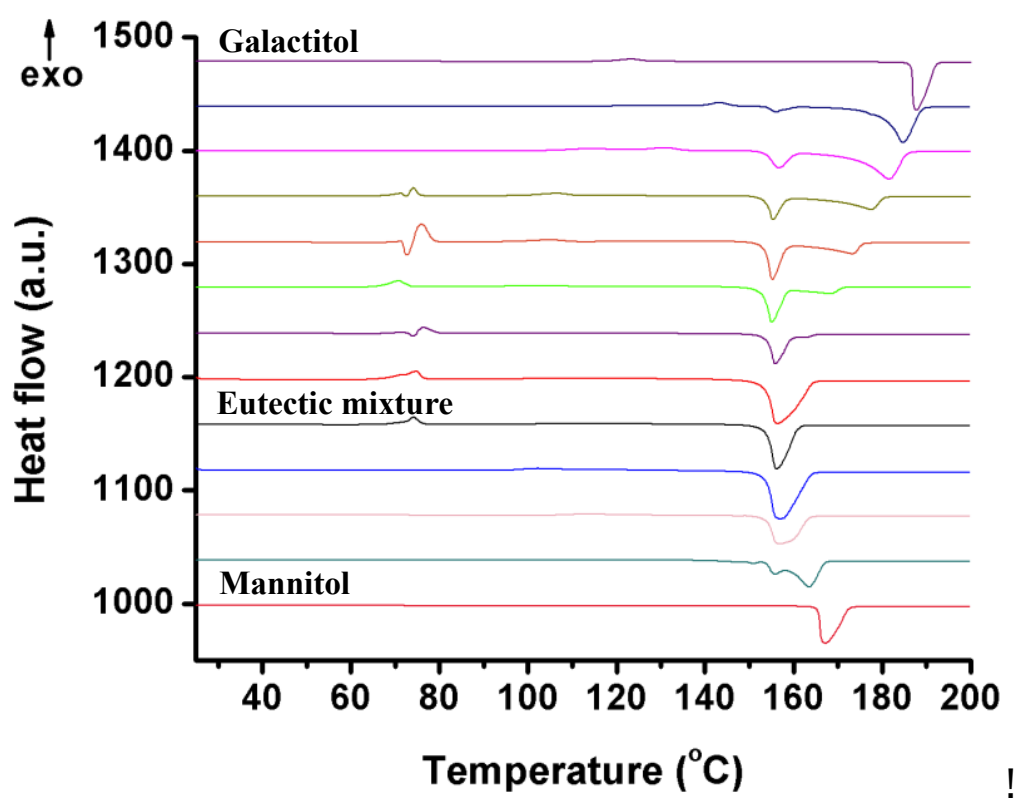

Figure 1. DSC melting curves of galactitol, mannitol, and their mixtures. The mannitol content in the mixture is $0,10,20,30,40,50,60,65,70,75,80,90,100 \%$ mol\%, respectively, for the 13 curves in the order from the top to the bottom. The ramp rate of $10{ }^{\circ} \mathrm{C} \min ^{-1}$ was employed for these experiments.

Hoersmansdoerfer reported that the melts of sugar alcohols are miscible in any proportion, and form a eutectic mixture upon cooling, which may be binary, ternary, or higher depending on the number of components used in the mixture. ${ }^{9}$ It was previously reported that galactitol and mannitol form a eutectic mixture at 50:50 molar ratio, and 
that the mixture displays a melting point around $153{ }^{\circ} \mathrm{C}$ and a heat of fusion of $282 \mathrm{~J} \mathrm{~g}^{-1}$. The thermograms shown in Figure 1 revealed that physical mixtures of galactitol and mannitol displayed two endothermic signals for all compositions explored except for the composition with a 30:70 molar ratio of galactitol and mannitol. The endothermic peak observed at the lower temperature corresponded to the melting point of D-mannitol whereas the peak that appeared at the relatively high temperature was assigned to that of galactitol. Due to their structural similarity, galactitol and mannitol were expected to be melt-miscible and form a nearly ideal solution at elevated temperatures. As the concentration of D-mannitol was increased in the aforementioned mixtures, the signals observed via DSC were gradually shifted to a lower temperature and eventually formed a single peak at $153.4{ }^{\circ} \mathrm{C}$. From this result it was concluded that they mixture formed a eutectic mixture when the concentration of mannitol reaches $70 \mathrm{~mol} \%$ in the mixture. We have also analyzed compositions with $65 \mathrm{~mol} \%$ and $75 \mathrm{~mol} \%$ of mannitol in the mixtures. The melting points of $65 \mathrm{~mol} \%$ and $75 \mathrm{~mol} \%$ mannitol mixtures were $153.5{ }^{\circ} \mathrm{C}$ and $153.4{ }^{\circ} \mathrm{C}$, close to the melting point of the eutectic mixture that is around $153.2{ }^{\circ} \mathrm{C}$. However, the thermogram for the eutectic mixture (black) is sharper than the thermograms of $65 \mathrm{~mol} \%$ (red) and $75 \mathrm{~mol} \%$ (blue) compositions as shown in Figure 1. The formation of the eutectic mixture was recognized by the appearance of a sharp and narrow endothermic peak. The broad endothermic peak for $65 \mathrm{~mol} \%$ and $75 \mathrm{~mol} \%$ compositions indicates the presence of a small amount of immiscible galactitol in the mixtures. Our results on the formation of the eutectic mixture at 30:70 molar ratio between galactitol and mannitol and its melting point and corresponding heat of fusion were consistent that reported in a very recent work.$^{20}$ 
As shown in Figure 1, the eutectic mixture exhibited a sharp melting point. The eutectic mixture may have different crystal structures or similar crystal structures with different lattice parameters compared to those of individual components. It is worth noting that the eutectic mixture has lower melting point than either sugar alcohol but displays a heat of fusion of approximately $97 \%$ of that of mannitol. The DSC curves for mixtures with 10 to 80 mol\% mannitol showed a small exothermic peak between $72.3{ }^{\circ} \mathrm{C}$ to $75.1{ }^{\circ} \mathrm{C}$ before melting. Such phenomena are often called cold crystallization. At higher scan rates, the mixtures form a solid glass on cooling, and recrystallize upon heating. In mannitol/sorbitol mixture, a cold crystallization peak was observed between $58{ }^{\circ} \mathrm{C}$ to $81.2{ }^{\circ} \mathrm{C}$ for compositions containing 10 to $70 \%$ sorbitol in the mixtures. ${ }^{18}$

Figure 2 shows the variation of the melting point for various sugar alcohols as a function of mannitol in the mixtures. The melting point of galactitol decreased the mannitol content increased in the mixture largely because galactitol dissolved in mannitol melt. On the other hand, the melting point of mannitol was only slightly affected by the presence of galactitol. It is interesting to note that in mannitol/sorbitol mixture, the melting point of mannitol decreased from $165^{\circ} \mathrm{C}$ to $115^{\circ} \mathrm{C}$ when the amount of sorbitol $\left(\mathrm{T}_{\mathrm{m}}=96.8{ }^{\circ} \mathrm{C}\right)$ was increased from 0 to $90 \%$ in the corresponding mixtures. ${ }^{18}$ As galactitol, mannitol, and sorbitol are stereoisomers, comparing the phase change behavior of mixture of D-mannitol/sorbitol and D-mannitol/galactitol can be helpful. 


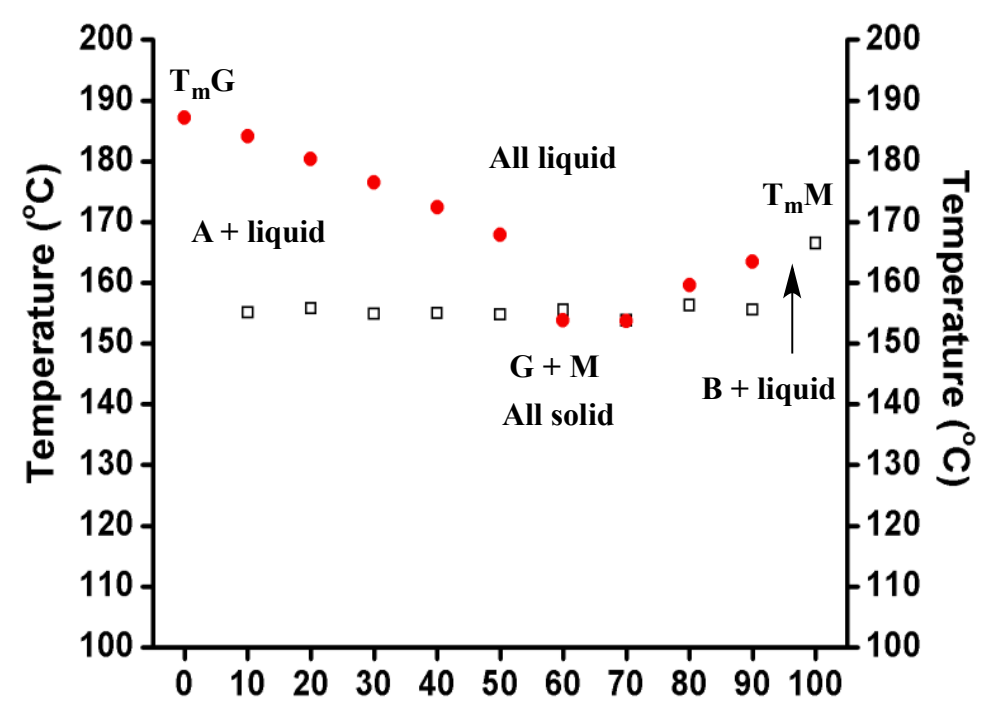

Amount of mannitol in mixtures (\%) !

Figure 2. The melting temperature of mannitol (open black squares) and galactitol (filled red circles) in relation to mole percent of mannitol in the mixtures. $T_{m} G$ and $T_{m} M$ refer to the melting points of galactitol and mannitol, respectively.

Figure 3 shows the corresponding cooling curves of the heating cycles shown in Figure 1. From these data, it appeared that galactitol, mannitol, and their mixtures exhibited large degree of subcooling. The material absorbed heat over a range of temperatures depending upon the heating rate. Upon cooling, the reverse transformation released the stored thermal energy at much lower temperatures than the melting point that were dependent on the cooling rates. Galactitol, mannitol, and their mixtures crystallize at temperatures below their melting points due to subcooling. The difference between the onset temperatures of melting and crystallization for mixtures was increased from $59{ }^{\circ} \mathrm{C}$ to $94{ }^{\circ} \mathrm{C}$ as the amounts of mannitol in the mixture was increased from 10 to $50 \mathrm{~mol} \%$, and then decreased to $52{ }^{\circ} \mathrm{C}$ when the quantity of mannitol reached $90 \mathrm{~mol} \%$ in the mixture at the scan rate of $10{ }^{\circ} \mathrm{C} \mathrm{min}^{-1}$. The difference between the melting point and 
the crystallization temperature for the eutectic point varied between $49.9{ }^{\circ} \mathrm{C}$ to $85.2{ }^{\circ} \mathrm{C}$ when ramp rates were increased from $0.5{ }^{\circ} \mathrm{C} / \mathrm{min}$ to $20{ }^{\circ} \mathrm{C} / \mathrm{min}$.
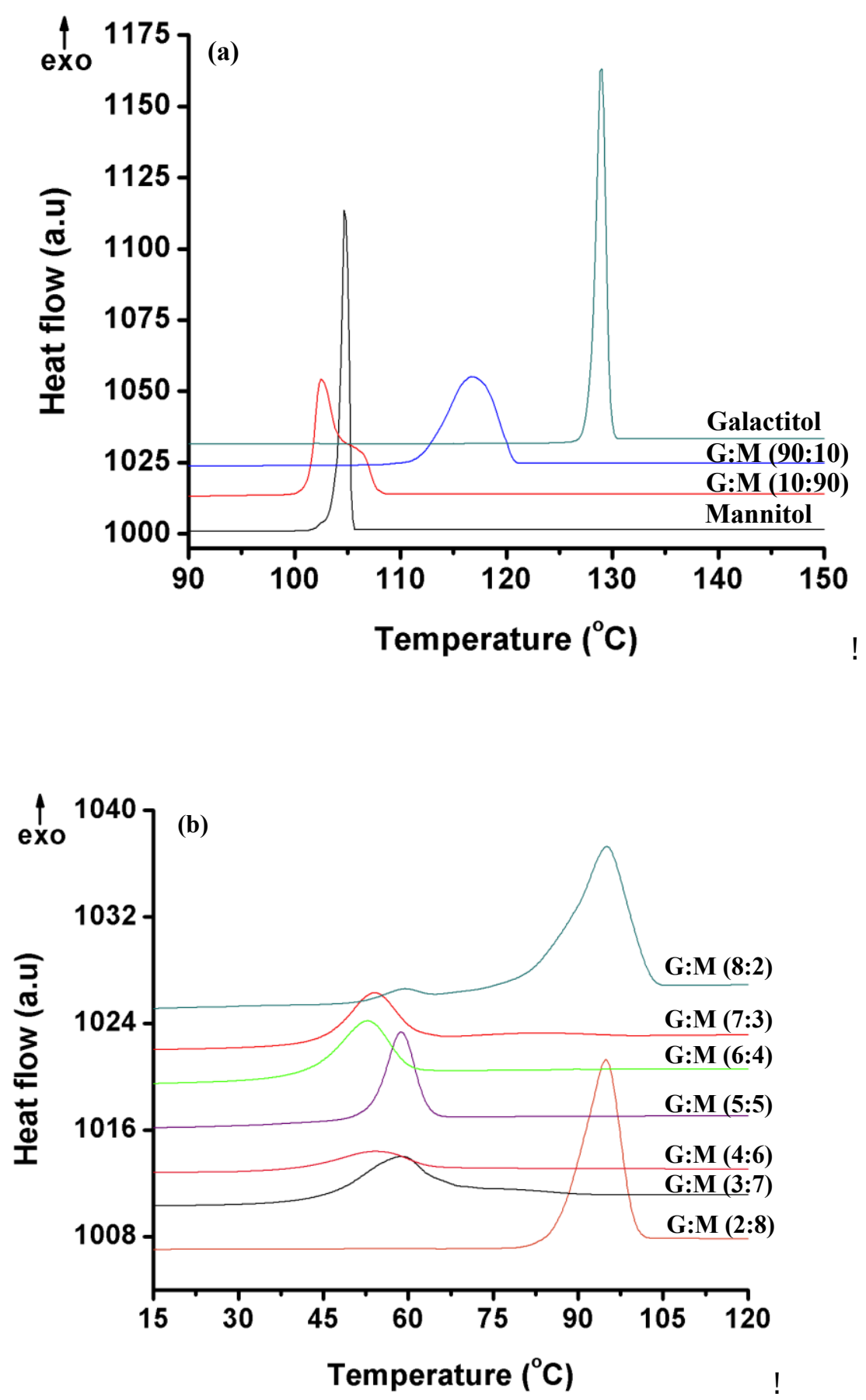

Figure 3. DSC cooling curves of galactitol, mannitol, and their mixtures. A ramp rate of $10{ }^{\circ} \mathrm{C} \min ^{-1}$ was employed for these experiments. 


\subsection{Effects of ramp rates on the thermophysical properties of a eutectic mixture}

Both DSC and the T-History methods can be used to characterize the phase change behavior of PCMs ${ }^{21}$ which can show phase separation, subcooling, slowcrystallization, or polymorphism. For PCMs with large subcooling, the dynamic DSC with a slow heating and cooling rates, usually 0.5 to $2{ }^{\circ} \mathrm{C} \mathrm{min}^{-1}$, can be used to determine the phase change behavior of PCMs with sufficient accuracy in a short period of time

compared to step mode DSC. ${ }^{21,22}$ In addition, high heating and cooling rates are often used to accelerate the screening of PCMs. We have performed a few DSC experiments with fast scan rates of $10{ }^{\circ} \mathrm{C} / \mathrm{min}$ and $20{ }^{\circ} \mathrm{C} / \mathrm{min}$. Such high heating rates suppress kinetically controlled processes, such as crystallization, so that the thermodynamic properties of unstable materials may be amplified. After the eutectic mixture was identified at the fast ramp rate, we have conducted DSC studies at slow ramp rates of 0.5 , 2.0, and $5.0{ }^{\circ} \mathrm{C} / \mathrm{min}$ to better understand the phase change behavior of the eutectic mixture.

Figures 4 and 5 show the scan rate dependency on the melting temperature and crystallization temperature as well as the corresponding enthalpies of a eutectic mixture of galactitol and mannitol. Gleaning the data reveals that the scan rate influenced the magnitudes of heat flow in the mixture during the melt transition. When the eutectic mixture was heated at a rate of $10{ }^{\circ} \mathrm{C} \mathrm{min}{ }^{-1}$ or higher, a peak that corresponded to a cold crystallization process was observed. All signals associated with melting processes and obtained at different scan rates displayed similar onset and peak temperatures. Collectively, these results suggested to us that the melting point of the eutectic mixture was independent of the scan rates. Indeed, as shown in Table 2, the eutectic mixture 
displayed a nearly constant melting point $\left(\mathrm{T}_{\mathrm{m}}\right)$ and heat of melting $\left(\Delta \mathrm{H}_{\mathrm{m}}\right)$ at different scan rates. The crystallization data shown in Table 2 correspond to the crystallization temperature $\left(\mathrm{T}_{\mathrm{c}}\right)$ and enthalpy of crystallization $\left(\Delta \mathrm{H}_{\mathrm{c}}\right)$ values, which were obtained from the respective DSC thermograms (Figure 5). The crystallization temperature of the eutectic mixture was increased from $67.9{ }^{\circ} \mathrm{C}$ to $104.6{ }^{\circ} \mathrm{C}$ when the scan rate was decreased from $20{ }^{\circ} \mathrm{C} \min ^{-1}$ to $0.5{ }^{\circ} \mathrm{C} \mathrm{min}{ }^{-1}$. Similarly, the heat of crystallization of the eutectic mixture was increased from $63.6 \mathrm{~J} \mathrm{~g}^{-1}$ to $196.8 \mathrm{~J} \mathrm{~g}^{-1}$, which showed a three-fold enhancement when the scan rate was decreased from $20^{\circ} \mathrm{C} \min ^{-1}$ to $0.5^{\circ} \mathrm{C} \min ^{-1}$. The variations in crystallization temperatures and their corresponding enthalpies at different scan rates are due to different structural ordering of crystals formed under those experimental conditions. A slow cooling rate of $0.5{ }^{\circ} \mathrm{C}$ or below would give sugar alcohol sufficient time for complete recrystallization and formation of perfect crystals. In some cases, the heat of crystallization was found to be lower than the heat of fusion, which may be due to an incomplete release of heat during the crystallization process.

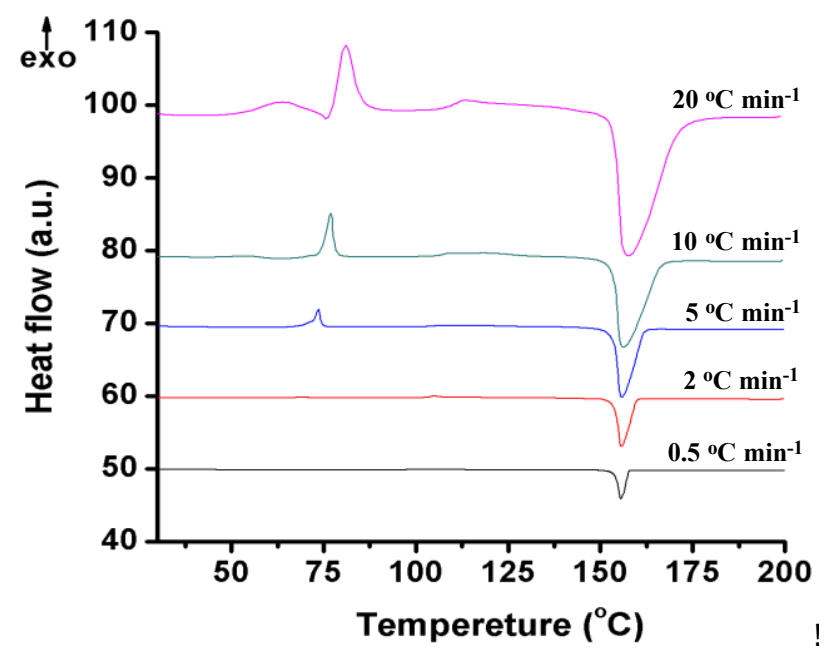


Figure 4. DSC heating curves of a 30:70 eutectic mixture of galactitol and mannitol at different scan rates.

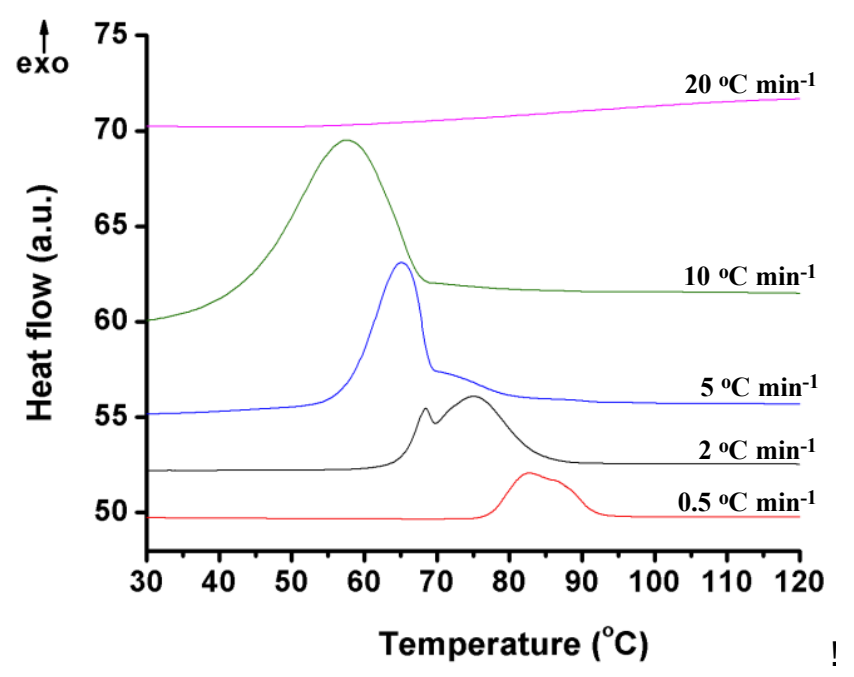

Figure 5. DSC cooling curves of a 30:70 eutectic mixture of galactitol and mannitol at different scan rates.

Table 2. A summary of the thermophysical properties displayed by a 30:70 eutectic mixture of galactitol and mannitol at various DSC scan rates

\begin{tabular}{ccccc}
\hline $\begin{array}{c}\text { Scan rate } \\
\left({ }^{\circ} \mathrm{C} \mathrm{min} \text { }^{-1}\right)\end{array}$ & $\mathrm{T}_{\mathrm{m}}\left({ }^{\circ} \mathrm{C}\right)$ & $\Delta \mathrm{H}_{\mathrm{m}}\left(\mathrm{J} \mathrm{g}^{-1}\right)$ & $\mathrm{T}_{\mathrm{c}}\left({ }^{\circ} \mathrm{C}\right)$ & $\Delta \mathrm{H}_{\mathrm{c}}\left(\mathrm{J} \mathrm{g}^{-1}\right)$ \\
\hline 0.5 & 154.5 & 282.2 & 104.6 & 196.8 \\
2 & 153.9 & 278.2 & 92.5 & 168.0 \\
5 & 153.8 & 291.5 & 84.1 & 137.9 \\
10 & 153.3 & 293.2 & 69.7 & 91.6 \\
20 & 153.1 & 288.0 & 67.9 & 63.6 \\
\hline
\end{tabular}




\subsection{Subcooling of a 30:70 eutectic mixture of galactitol and mannitol}

Sugar alcohols commonly exhibit supercooling. For example, erythritol crystallizes between $60{ }^{\circ} \mathrm{C}$ to $100{ }^{\circ} \mathrm{C}$ in a range, ${ }^{10}$ mannitol has a crystallization temperature of $111.0^{\circ} \mathrm{C}$ to 115.3 at various scan rates, ${ }^{19}$ and galactitol crystallizes at 102 ${ }^{\circ} \mathrm{C},{ }^{13}$ which are all lower than their respective melting points. When sugar alcohols melt, they form highly viscous syrup that restricts the diffusion of molecules from the melt to the nucleus, resulting in slow nucleation and crystal growth. Moreover, intermolecular hydrogen bonding between the molecules in the melt also affects the diffusion rate of individual molecules from the melt to the active crystal sites. ${ }^{23}$ Thus, a delay in nucleation and crystal growth result in the appearance of considerable degree of subcooling phenomena in sugar alcohols. Similarly, when a eutectic mixture first melts and then crystallizes, subcooling can occur and parts of the mixture may not crystallize even upon cooling below the melting temperature. Thus, subcooling is a kinetic issue which interferes with the heat withdrawal from PCMs during the crystallization process and can be reduced by adding sparingly soluble inorganic salts. ${ }^{24}$ To overcome the subcooling issue observed in the aforementioned eutectic mixture, small quantities of sparingly soluble inorganic salts, such as calcium pyrophosphate $\left(\mathrm{Ca}_{2} \mathrm{P}_{2} \mathrm{O}_{7}\right)$, aluminum phosphate $\left(\mathrm{AlPO}_{4}\right)$, silver iodide $(\mathrm{AgI})$, graphite foam or graphite powder were added independently to initiate the freezing process. These additives can potentially serve as nucleating agents wherein the sugar alcohol can crystallize with little or no subcooling. The DSC data reported in Table 3 revealed that there was no significant change in the onset melting point of the eutectic mixture, either with and without the addition of various nucleating agents. However, the heat of melting of the eutectic mixture decreased 
up to $4 \%$ with nucleating agents equal to $1.0 \mathrm{wt} \%$ or below, with the exception of silver iodide where the addition of $0.5 \mathrm{wt} \%$ of the inorganic material increased the heat of melting by $3 \%$ from its initial value. While the $3 \%$ or $4 \%$ difference is comparable to the measurement uncertainty, the eutectic mixture containing $6.5 \mathrm{wt} \%$ oxygen plasma treated ultrathin graphite foam caused the heat of melting of the eutectic mixture to decrease by $13 \%$ with no change in the melting point, an effect that may be due to an anomalous interaction between the PCM and the inner surface of the nano-sized pores in the graphite. $^{25}$

When compared to the small effects on the melting temperature, the aforementioned nucleating agents influenced the crystallization temperatures. For the graphite powder/eutectic mixture, in particular, the melting point and heat of melting were found to be the same as the neat eutectic mixture whereas there was a $10{ }^{\circ} \mathrm{C}$ increase in the crystallization temperature with an increase of $47 \mathrm{~J} \mathrm{~g}^{-1}$ in the corresponding heat of crystallization. Indeed, samples mixed with nucleating agents showed increased crystallization temperatures and improved heat recoveries, although the observed heat of crystallization is still lower than the heat of melting.

Table 3. A summary of the thermal properties displayed by a 30:70 eutectic mixture of galactitol and mannitol mixed with various nucleating agents. The ramp rate of $5{ }^{\circ} \mathrm{C}$ $\min ^{-1}$ was employed for these experiments.

\begin{tabular}{|c|c|c|c|c|c|}
\hline \multicolumn{2}{|c|}{ Nucleating agent } & \multirow{2}{*}{$\mathrm{T}_{\mathrm{m}}\left({ }^{\circ} \mathrm{C}\right)$} & \multirow{2}{*}{$\Delta \mathrm{H}_{\mathrm{m}}\left(\mathrm{J} \mathrm{g}^{-1}\right)$} & \multirow{2}{*}{$\mathrm{T}_{\mathrm{c}}\left({ }^{\circ} \mathrm{C}\right)$} & \multirow{2}{*}{$\Delta \mathrm{H}_{\mathrm{c}}\left(\mathrm{J} \mathrm{g}^{-1}\right)$} \\
\hline Type & $\begin{array}{c}\text { Amount } \\
\text { (wt \%) }\end{array}$ & & & & \\
\hline None & - & 153.8 & 291.5 & 84.1 & 137.9 \\
\hline Silver iodide & 0.5 & 153.4 & 300.3 & 93.9 & 170.1 \\
\hline
\end{tabular}




\begin{tabular}{cccccc} 
Silver iodide & 1.0 & 154.1 & 287.2 & 91.8 & 164.0 \\
Silver iodide & 5.0 & 154.1 & 244.7 & 94.2 & 151.2 \\
$\begin{array}{c}\text { Calcium } \\
\text { pyrophosphate }\end{array}$ & 1.0 & 153.6 & 279.7 & 87.4 & 140.5 \\
$\begin{array}{c}\text { Calcium } \\
\text { pyrophosphate }\end{array}$ & 5.0 & 153.8 & 283.6 & 85.2 & 153.5 \\
$\begin{array}{c}\text { Aluminum } \\
\text { phosphate }\end{array}$ & 1.0 & 154.0 & 284.4 & 89.8 & 152.9 \\
$\begin{array}{c}\text { Aluminum } \\
\text { phosphate }\end{array}$ & 5.0 & 153.6 & 263.5 & 94.3 & 152.4 \\
$\begin{array}{c}\text { Synthetic } \\
\text { graphite }\end{array}$ & 0.1 & 154.1 & 287.4 & 93.0 & 185.1 \\
$\begin{array}{c}\text { Natural graphite } \\
\text { Ultrathin }\end{array}$ & 0.1 & 153.9 & 291.3 & 93.1 & 174.3 \\
$\begin{array}{c}\text { graphite foam } \\
\text { (oxygen plasma } \\
\text { treated) }\end{array}$ & 6.0 & 153.7 & 252.8 & 93.7 & 141.7 \\
\hline
\end{tabular}

\subsection{Thermal and cyclic stability of a eutectic mixture}

The thermal stabilities of various sugar alcohols and the aforementioned eutectic mixture were analyzed using thermogravimetric analysis. Figure 6 indicates that the eutectic mixture displays a higher thermal stability than pure galactitol or mannitol. The decomposition temperatures of galactitol, mannitol, and the 30:70 eutectic mixture were measured to be 295,300 , and $313{ }^{\circ} \mathrm{C}$, respectively. 


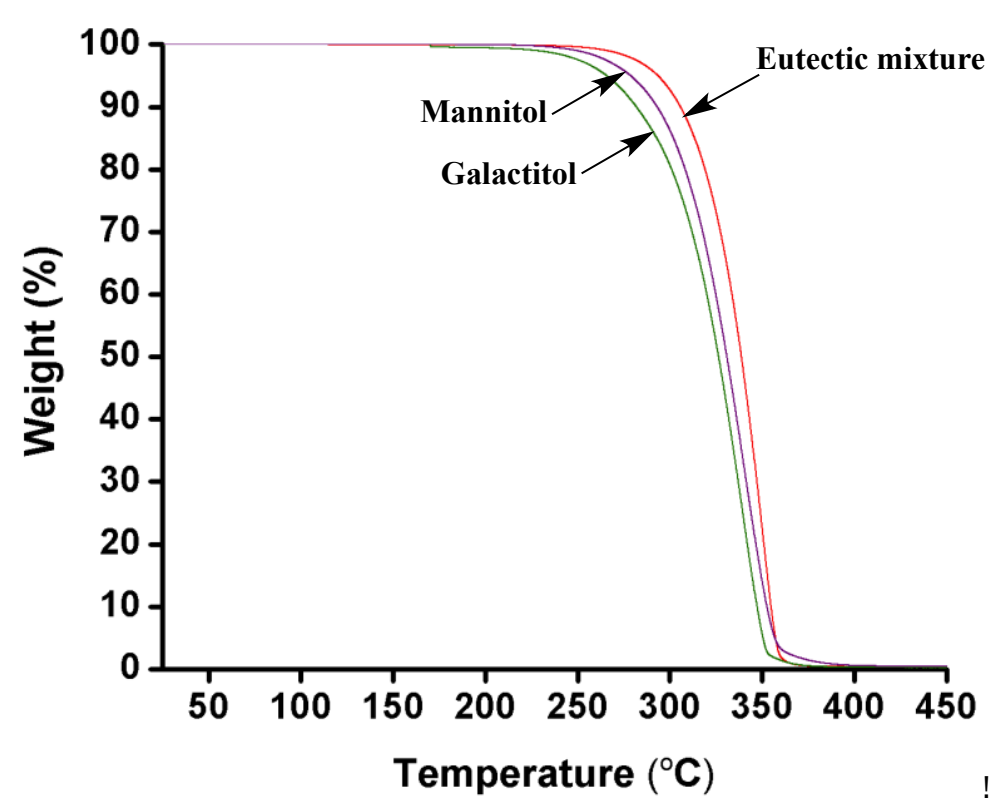

Figure 6. Thermogravimetric analysis of galactitol, mannitol, and a 30:70 eutectic mixture. A ramp rate of $10{ }^{\circ} \mathrm{C} \mathrm{min}^{-1}$ was employed for these experiments.

When the eutectic mixture was cycled repeatedly through 20 heating and cooling cycles under an atmosphere of nitrogen or air at the scan rate of $5{ }^{\circ} \mathrm{C} \min ^{-1}$, the phase change appears to be reversible. Figure 7 shows 20 heating and cooling cycles of the eutectic mixture under atmospheres of nitrogen and air at the scan rate of $5{ }^{\circ} \mathrm{C} \min ^{-1}$. A small melting peak was observed before melting for the eutectic mixture performed under an atmosphere of air which may be due to the formation of some imperfect crystals. The small endothermic peak was not observed in DSC thermograms for the eutectic mixture performed under an atmosphere of nitrogen. After 20 cycles under air, the melting point of the eutectic mixture decreased by $2.9 \%$ whereas the crystallization temperature remained unchanged, and there was $11.2 \%$ decrease in the heat of fusion and $4.8 \%$ reduction in heat of crystallization of the eutectic mixture from their initial values. Further cyclic test on this sample was not performed, as we were interested in studying 
the cyclic stability of the eutectic mixture under the nitrogen atmosphere to get some insight into material's thermal response under inert atmosphere. The eutectic mixture performed 100 heating and cooling cycles under nitrogen atmosphere showed consistent melting points, high heats of fusion, and high thermal stabilities. Table 4 summarizes various thermal data for a eutectic mixture that was subjected to 100 thermal cyclic tests under nitrogen atmosphere at scan rate of $5{ }^{\circ} \mathrm{C} / \mathrm{min}$. After 100 cycles, the melting point of the eutectic mixture remained unchanged, and there was only $4 \%$ decrease in the heat of fusion and a $2 \%$ reduction in the melting point of the eutectic mixture from their initial values. In comparison, the crystallization temperature $\left(\mathrm{T}_{\mathrm{c}}=87.4{ }^{\circ} \mathrm{C}\right)$ and heat of crystallization $\left(\Delta \mathrm{H}_{\mathrm{c}}=139.2 \mathrm{~J} \mathrm{~g}^{-1}\right)$ were markedly increased from their initial values at the end of $20^{\text {th }}$ cycle.

Recently, Nomura et al. have estimated the degradation temperature of different types of sugar alcohols and their eutectic mixtures by monitoring the duration at which heat of fusion of PCM reached various degradation values by holding the sample at temperature ten degrees higher than the melting point of PCMs. They found that ringstructured inositol has higher thermal stability than the chain-structured sugar alcohols such as mannitol and dulcitol. They have also reported that the rate of degradation of eutectic mixtures of inositol/dulcitol/mannitol was smaller than the individual component because of lower melting point of the eutectic mixture required lower holding temperature for keeping heat storage conditions. For the eutectic mixture of dulcitol (or galactitol) and mannitol, the duration of which the enthalpy of fusion reached the degradation value was higher than the eutectic mixture of inositol/dulcitol/mannitol 
because of the high initial value of enthalpy of fusion for dulcitiol/mannitol eutectic mixture. $^{20}$
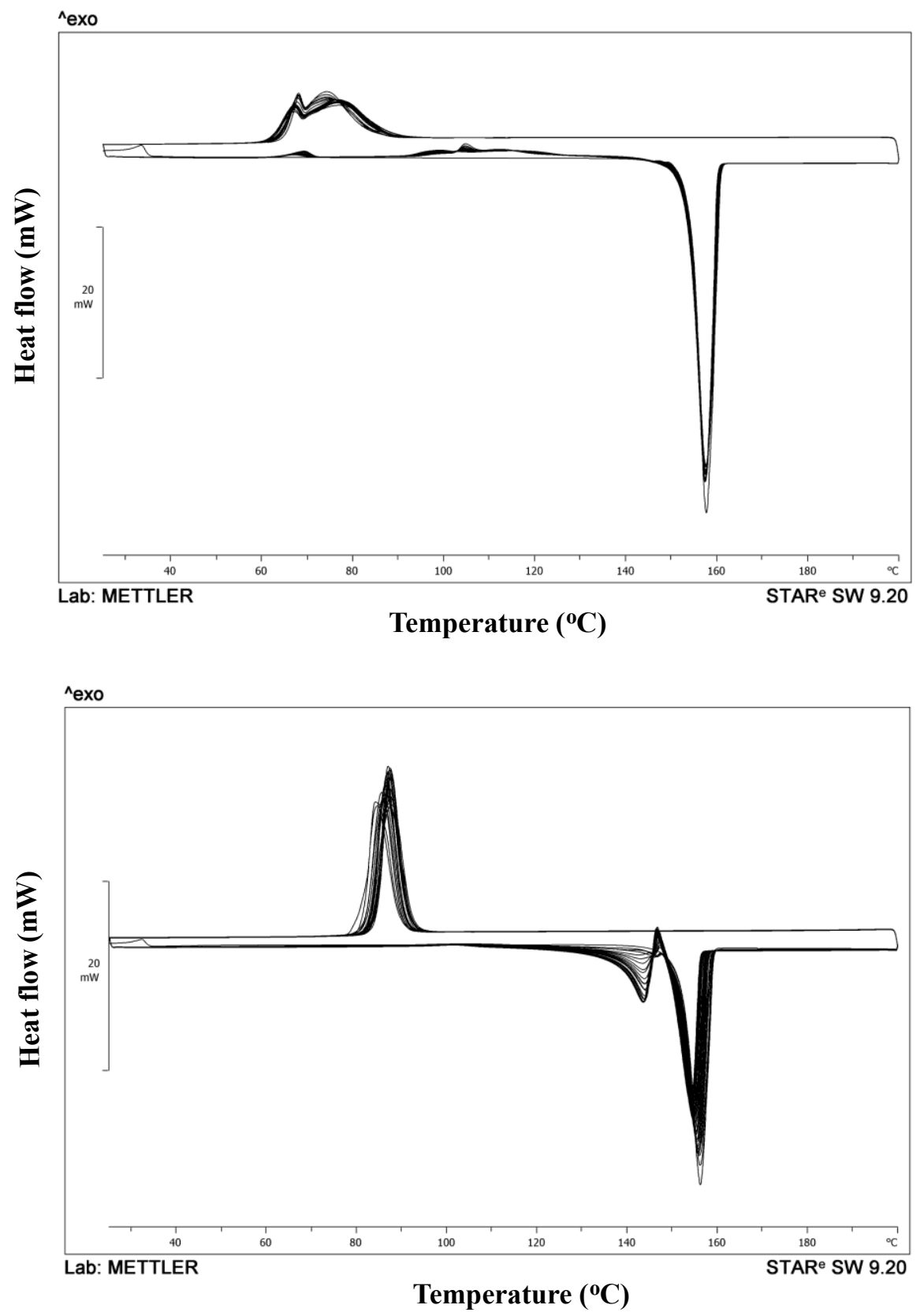

Figure 7. DSC thermograms of 20 heating and cooling cycles for a 30:70 eutectic mixture of galactitol and mannitol in presence of nitrogen atmosphere (top) and air atmosphere (bottom). A ramp rate of $5^{\circ} \mathrm{C} \min ^{-1}$ was employed for these experiments. 
Table 4. Melting points, crystallization temperatures, and corresponding enthalpies of eutectic mixture before and after 100 heating and cooling cycles at $5{ }^{\circ} \mathrm{C} / \mathrm{min}$ ramp rate.

\begin{tabular}{ccccc}
\hline No. of cycles & $\mathrm{T}_{\mathrm{m}}\left({ }^{\circ} \mathrm{C}\right)$ & $\Delta \mathrm{H}_{\mathrm{m}}\left(\mathrm{J} \mathrm{g}^{-1}\right)$ & $\mathrm{T}_{\mathrm{c}}\left({ }^{\circ} \mathrm{C}\right)$ & $\Delta \mathrm{H}_{\mathrm{c}}\left(\mathrm{J} \mathrm{g}^{-1}\right)$ \\
\hline 0 & 153.4 & 292.2 & 87.1 & 134.3 \\
20 & 153.1 & 289.2 & 87.3 & 136.5 \\
40 & 152.6 & 288.9 & 88.0 & 149.4 \\
60 & 152.2 & 286.4 & 87.8 & 144.6 \\
80 & 151.8 & 276.0 & 87.6 & 145.6 \\
100 & 151.4 & 275.9 & 87.4 & 144.7 \\
\hline
\end{tabular}

\subsection{FT-IR spectroscopy}

FTIR measurements were performed on the aforementioned eutectic mixtures that were tested for their cyclic stabilities under air and nitrogen gas atmosphere. The corresponding FTIR spectra showed significant differences in the $\mathrm{O}-\mathrm{H}$ and $\mathrm{C}-\mathrm{H}$ stretching frequencies between 2500 and $3700 \mathrm{~cm}^{-1}$ as well as a difference in the $\mathrm{C}-\mathrm{H}$ vibrations in the range of 1400 and $1200 \mathrm{~cm}^{-1}$ for different polymorphic forms of mannitol. Solé et. al. ${ }^{13}$ observed two peaks in FTIR spectra for galactitol $\left(1740 \mathrm{~cm}^{-1}\right.$ and $\left.1650 \mathrm{~cm}^{-1}\right)$ and mannitol $\left(1730 \mathrm{~cm}^{-1}\right.$ and $\left.1640 \mathrm{~cm}^{-1}\right)$ after a series of cyclic tests; the signals may correspond to vibrations of CO-double bonds of ketones, acids or aldehydes. These results suggested to us that the sugar alcohols in their pure forms oxidized during the cyclic tests. On the other hand, as shown in Figure 8, the FT-IR spectra acquired for the eutectic mixture before and after 20 heating and cooling cycles, both under air and 
nitrogen gas, correspond to different polymorphic phases of D-Mannitol such as $\alpha$, $\beta$, and $\delta$, confirmed from the spectra reported by Burger et al. ${ }^{17}$ This indicated that the eutectic mixture was stable under the experimental conditions described above.

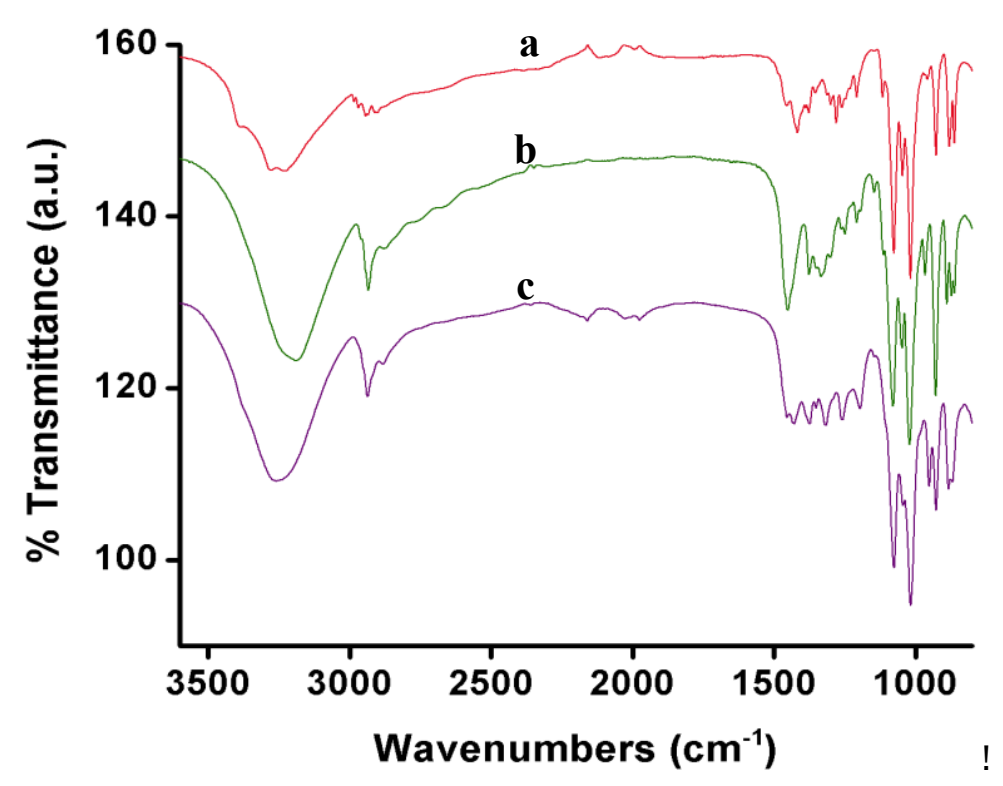

Figure 8. FTIR spectra of the eutectic mixture (a) before DSC experiment (b) after 20 DSC heating/cooling cycles in air (c) after 20 DSC heating/cooling cycles in nitrogen gas 3.6 Powder X-ray diffraction analysis

Figure 9 shows the powder X-ray diffraction patterns of two polymorphs of galactitol as well as sugar alcohol mixtures containing different amounts of mannitol. The powder diffraction patterns obtained were in good agreement with literature data. ${ }^{26-28}$ For comparison, the eutectic mixture displayed shown sharp peaks at lower 2- $\theta$, which confirmed the crystalline nature of the mixture. By comparing the diffraction patterns from the literature and the reference samples $(\alpha$ and $\beta)$, it can be concluded that the eutectic mixture contained the $\alpha, \beta$, and $\delta$ forms of mannitol (Table 5). Moreover, the mixture appears to contain the $\delta$ form as a major component with small amounts of $\alpha$ and 
$\beta$ forms. For comparison, the diffraction pattern collected for 1:1 mixture of galactitol mannitol mixture to us that of only the $\alpha$ form of mannitol was present. Table 5 contains a summary of various X-ray data.

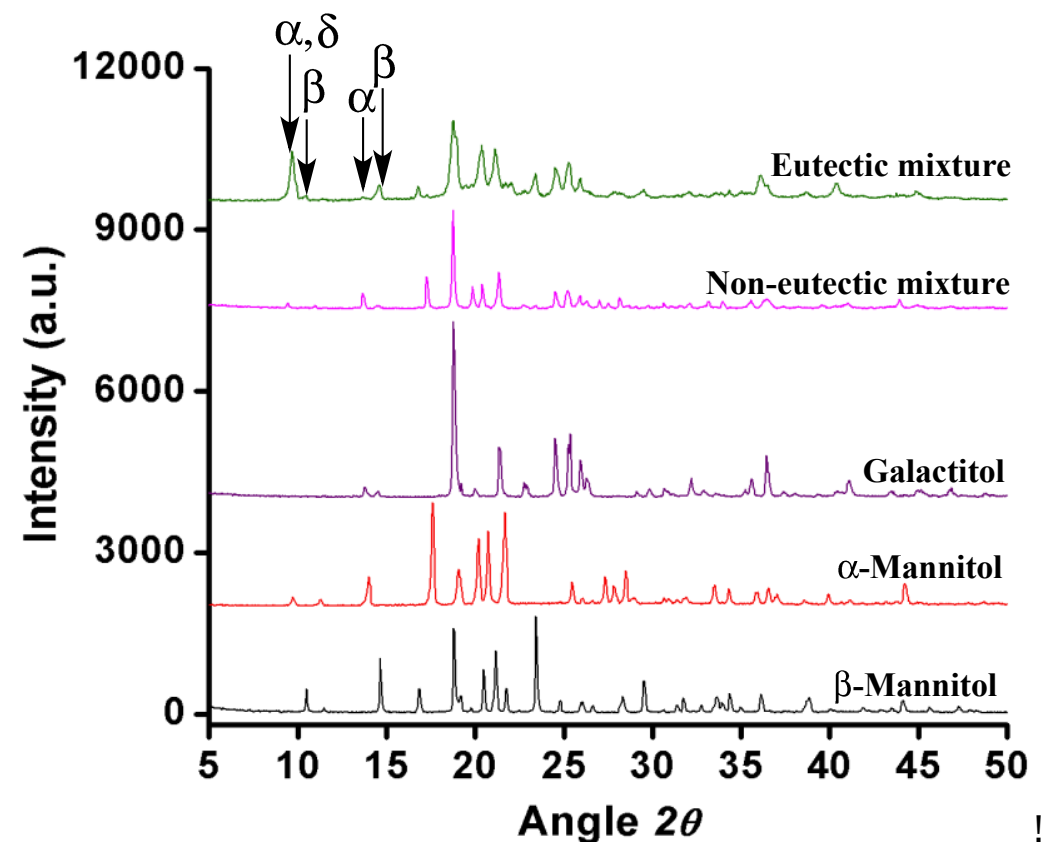

Figure 9. XRPD patterns of mannitol polymorphs and various galactitol/mannitol mixtures.

Table 5. A summary of powder X-ray data for various samples.

Sample

Eutectic mixture

$(\delta, \alpha$, and $\beta$-mannitol)

Non-eutectic mixture ${ }^{a}$

( $\alpha$-Mannitol)

$\alpha$-mannitol ${ }^{b}$
Position of peak $2 \theta$ value

$\delta$ form: 10.08 (Intense peak) and 14.64 (weak) $\beta$ form: 10.44 and 14.72 (relatively intense peak) $\alpha$ form: 9.84 (overlapped with $\delta$-peak) and 13.64 
${ }^{a}$ The composition of non-eutectic is 50:50 mol\% between galactitol and mannitol.

${ }^{a}$ The sample was prepared by heating commercially-available $\beta$-mannitol to $200{ }^{\circ} \mathrm{C}$ for 30 min and cooling the melt slowly to room temperature on aluminum foil.

\subsection{Thermal conductivity of galactitol and mannitol mixtures}

A laser flash technique was used to measure the thermal diffusivity $(\alpha)$ of various galactitol/mannitol mixtures. The thermal conductivity $(\kappa)$ was calculated by using the equation $\alpha=k d\left(\sum x_{i} \rho_{i} C_{p, i}\right)$, where $x_{i}$ is the mass fraction of each component, $\rho_{i}$ is the density of the mixture, and $C_{p}$ is the specific heat capacity of each component. The relative uncertainty in the obtained thermal conductivity is about $10 \%$. The thermal conductivity reached a minimum on a sample that contained 50 mol\% of mannitol. The compositions of mixtures that contained 40 to $70 \mathrm{~mol} \%$ mannitol displayed a thermal conductivity below $0.4 \mathrm{Wm}^{-1} \mathrm{~K}^{-1}$, which is typical for many organic materials used in phase change applications. On further increasing the concentration of mannitol in the mixture, the thermal conductivity increased and reached the maximum value $0.6 \mathrm{Wm}^{-1} \mathrm{~K}^{-}$

${ }^{1}$. We were unable to measure the thermal conductivity of mixtures containing less than $30 \mathrm{~mol} \%$ mannitol due to the poor structural integrity and brittleness of the samples. 


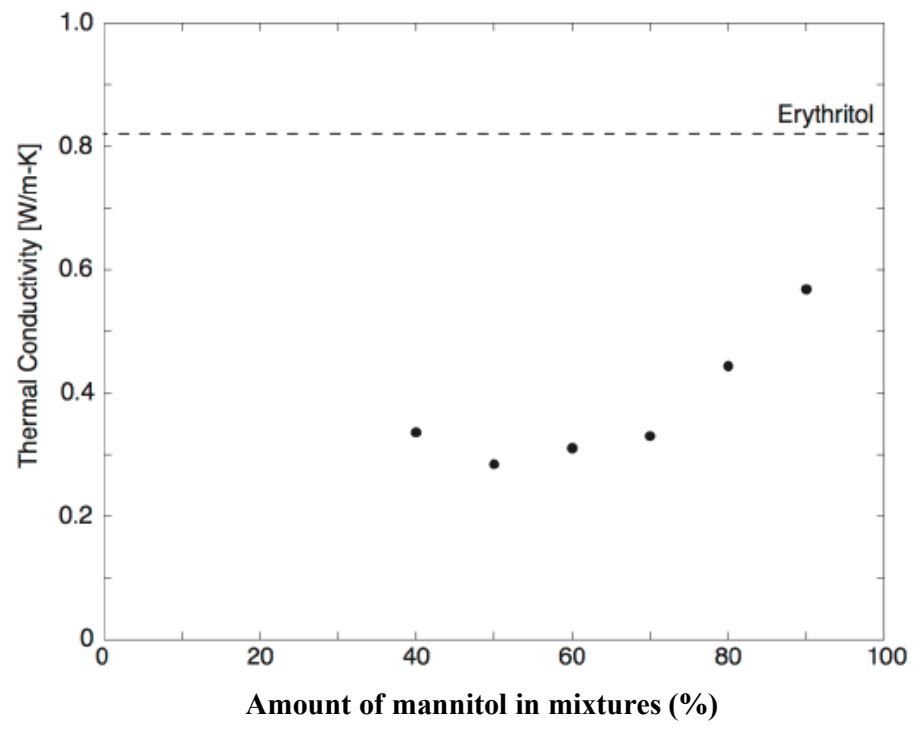

Figure 10. Measured thermal conductivities of various sugar alcohol mixtures with a relative uncertainty of about 10

\section{Conclusions}

Mixtures of mannitol and galactitol were explored as potential phase change materials for use in medium-temperature thermal energy storage applications. Based on a series DSC studies, galactitol was found to display a $\mathrm{T}_{\mathrm{m}}=187^{\circ} \mathrm{C}$ and $\Delta \mathrm{H}_{\text {fus }}=354 \mathrm{~J} \mathrm{~g}^{-1}$ whereas mannitol exhibited a $\mathrm{T}_{\mathrm{m}}=166{ }^{\circ} \mathrm{C}, \Delta \mathrm{H}=300.6 \mathrm{~J} \mathrm{~g}^{-1}$. The sugars were found to form a eutectic mixture at galactitol to mannitol molar ratio of 30:70, which displayed a sharp melting point of $\mathrm{T}_{\mathrm{m}}=153.4{ }^{\circ} \mathrm{C}$, which is lower than that of either sugar alcohol, as well as a latent heat of melting value $\Delta \mathrm{H}_{\mathrm{m}}=292 \mathrm{~J} \mathrm{~g}^{-1}$. The eutectic mixture contains the $\delta$-form of mannitol as a major component with small fractions of the $\alpha$-and $\beta$-forms. Varying the temperature ramp rates was found to have no effect on the heat of melting or the melting point of eutectic mixture. However, the heat and the temperature of crystallization of eutectic mixture were improved by reducing the ramp rate from $20{ }^{\circ} \mathrm{C}$ $\min ^{-1}$ to $0.5{ }^{\circ} \mathrm{C} \min ^{-1}$. In addition, the temperature and enthalpy of crystallization were 
also improved by $11 \%$ and $34 \%$ by adding 0.1 to $0.5 \mathrm{wt} \%$ graphite or silver iodide as a nucleating agent. DSC, TGA, and FTIR spectroscopy confirmed that the eutectic mixture displayed good cyclic, thermal, and chemical stability compared to its individual components under nitrogen or air. With further efforts to suppress the subcooling and the associated reduction of the heat of crystallization compared to heat of fusion, the aforementioned mixture represents a promising heat storage material due to its melting point, which in the range required for medium temperature range thermal energy storage applications, high heat of fusion, non-corrosiveness and high thermal cyclic stability.

\section{Acknowledgements}

We thank Dr. Steve Vienna for his help on X-ray powder diffraction measurements. We would also like to thank Dr. Iskandar Kholmanov for providing oxygen plasma treated ultrathin graphite foam and Dr. Dan P. Sellan for conducting thermal diffusivity measurements on sugar mixtures. This work is supported by the US Department of Energy ARPA-E HEATS program, Award \# DE-AR0000178.

\section{References}

[1] Gur 1, Sawyer K, Prasher R. Searching for a better thermal battery. Science 2012; 335:14545.

[2] Sharma A, Tyagi VV, Chen CR, Buddhi D. Review on thermal energy storage with phase change materials and applications. Renew Sust Energ Rev 2009; 13:318-45.

[3] Rathod MK, Banerjee J. Thermal stability of phase change materials used in latent heat energy storage systems: A review. Renew Sust Energ Rev. 2013;18:246-58.

[4] Kenisarin M, Mahkamov K. Solar energy storage using phase change materials. Renew Sust Energ Rev 2007;11:1913-65. 
[5] Farid MM, Khudhair AM, Razack SAK, Al-Hallaj S. A review on phase change energy storage: materials and applications. Energ Convers Manage. 2004;45:1597-615.

[6] Zalba B, Marín JM, Cabeza LF, Mehling H. Review on thermal energy storage with phase change: materials, heat transfer analysis and applications. Appl Therm Eng 2003;23:251-83

[7] Kaizawa A, Maruoka N, Kawai A, Kamano H, Jozuka T, Senda T, et al. Thermophysical and heat transfer properties of phase change material candidate for waste heat transportation system. Heat Mass Transfer 2008;44:763-9.

[8] Kumaresan G, Velraj R, Iniyan S. Thermal analysis of D-mannitol for use as phase change material for latent heat storage. J Appl Sci 2011;11:3044-8.

[9] Hormansdorfer G. Latent heat storage material and use thereof; 1989.

[10] Kakiuchi H, Yamazaki M, Yabe M, Chihara S, Terunuma Y, Sakata Y, et al. A study of erythritol as phase change material. IEA Annex 10- PCMs and chemical reactions for thermal energy storage, Sofia, Bulgaria; 1998.

[11] Shukla A, Buddhi D, Sawhney RL. Thermal cycling test of few selected inorganic and organic phase change materials. Renew Energ 2008;33:2606-14.

[12] Ji H, Sellan DP, Pettes MT, Kong X, Ji J, Shi L, et al. Enhanced thermal conductivity of phase change materials with ultrathin-graphite foams for thermal energy storage. Energy Environ Sci 2014;7:1185-92.

[13] Solé A, Neumann H, Niedermaier S, Martorell I, Schossig P, Cabeza LF. Stability of sugar alcohols as PCM for thermal energy storage. Sol Energ Mat Sol C. 2014;126:125-34.

[14] Barone G, Gatta GD, Ferro D, Placente V. Enthalpies and entropies of sublimation, vaporization and fusion of nine polyhydric alcohols. J Chem Soc Faraday Trans. 1990;86:75-9. [15] Raemy A, Schweizer TF. Thermal behaviour of carbohydrates studied by heat flow 
calorimetry. J Therm Anal 1983;28:95-108.

[16] Barreneche C, Gil A, Sheth F, Fernández AI, Cabeza LF. Effect of D-mannitol polymorphism in its thermal energy storage capacity when it is used as PCM. Sol Energy. 2013;94:344-51.

[17] Burger A, Henck J-O, Hetz S, Rollinger JM, Weissnicht AA, Stöttner H. Energy/temperature diagram and compression behavior of the polymorphs of D-mannitol. J Pharm Sci. 2000;89:457-68.

[18] Gombás Á, Szabó-Révész P, Regdon Jr. G, Erős I. Study of thermal behaviour of sugar alcohols. J Therm Anal Calorim 2003;73:615-21.

[19] Pitkånen I, Perkkalainen P, Rautiainen H. Thermoanalytical studies on phases of Dmannitol. Thermochim Acta 1993;214:157-62.

[20] Nomura T, Zhu C, Sagara A, Okinaka N, Akiyama T. Estimation of thermal endurance of multicomponent sugar alcohols as phase change materials. Appl Therm Eng 2015;75:481-6. [21] Rathgeber C, Miró L, Cabeza LF, Hiebler S. Measurement of enthalpy curves of phase change materials via DSC and T-History: when are both methods needed to estimate the behaviour of the bulk material in applications? Thermochim Acta. 2014;596:79-88. [22] Günther E, Hiebler S, Mehling H, Redlich R. Enthalpy of phase change materials as a function of temperature: required accuracy and suitable measurement methods. Int $\mathbf{J}$ Thermophys. 2009;30:1257-69.

[23] Jesus AJL, Nunes SCC, Silva MR, Beja AM, Redinha JS. Erythritol: crystal growth from the melt. Int J Pharm 2010;388:129-35.

[24] Kakiuchi H, Chihara S, Yamazaki M, Isaka T. Heat storage compositions; 1997. [25] Nomura T, Okinaka N, Akiyama T. Impregnation of porous material with phase change 
material for thermal energy storage. Mater Chem Phys. 2009;115:846-50.

[26] Hulse WL, Forbes RT, Bonner MC, Getrost M. The characterization and comparison of spray-dried mannitol samples. Drug Dev Ind Pharm 2009;35:712-8.

[27] Yoshinari T, Forbes RT, York P, Kawashima Y. Moisture induced polymorphic transition of mannitol and its morphological transformation. Int J Pharm 2002;247:69-77.

[28] Cornel J, Kidambi P, Mazzotti M. Precipitation and transformation of the three polymorphs of D-mannitol Ind Eng Chem Res. 2010;49:5854-62. 


\section{Graphical Abstract:}

Cyclic stability of the eutectic mixture of galactitol and D-mannitol

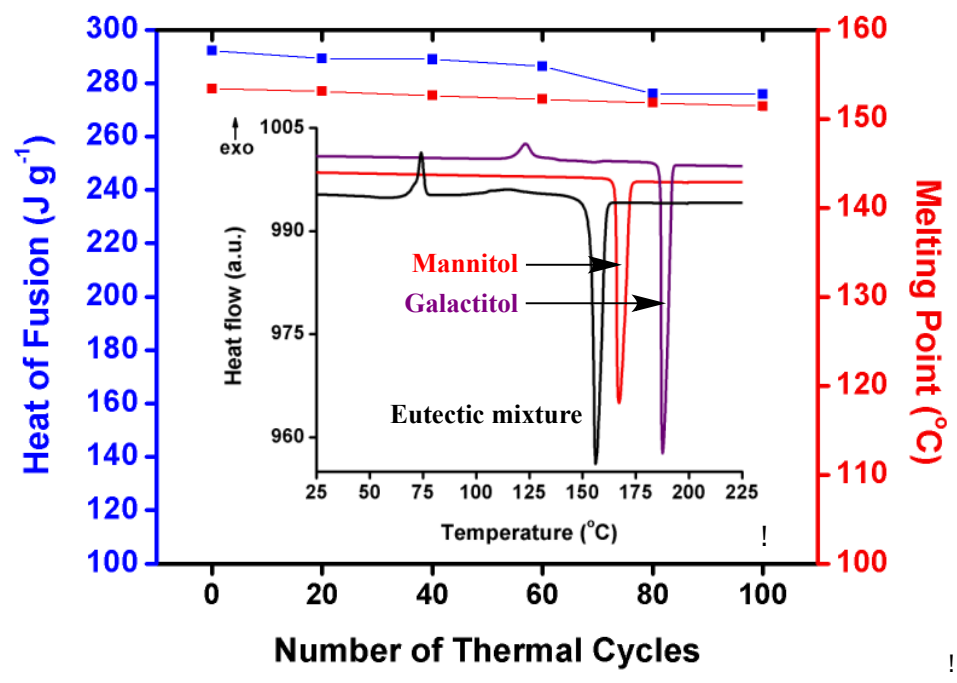

